Research Article

\title{
Study of clinical presentation and histopathological patterns of ovarian cancer in a tertiary care centre
}

\author{
Padma Krishnaswamy, Ashwini Nayak, Chaitra Shivananjiah*, Asha Swarup, \\ Amulya Cherukumudi, Preetam Raj Chandran
}

Department of Obstetrics \& Gynaecology, M. S. Ramaiah Medical College, Bangalore, India

Received: 02 November 2015

Accepted: 19 November 2015

*Correspondence:

Dr. Chaitra Shivananjiah,

E-mail: chaittra.shiv@gmail.com

Copyright: () the author(s), publisher and licensee Medip Academy. This is an open-access article distributed under the terms of the Creative Commons Attribution Non-Commercial License, which permits unrestricted non-commercial use, distribution, and reproduction in any medium, provided the original work is properly cited.

\section{ABSTRACT}

Background: One of the leading gynecological malignancies is ovarian cancer. The current study was done to study the histopathological pattern and clinical presentation of ovarian cancer in a tertiary care centre. The objective of the study was to study the clinical presentation, histopathological types of ovarian cancer and the outcome of the management.

Methods: A retrospective study of the patients treated at the M. S. Ramaiah Medical College and Teaching hospital, Bangalore from a total period of 5 years, from January 2009 - January 2014. The epidemiological data and histopathological analysis of the ovarian cancer was done.

Results: In the present study, a total of 106 ovarian cancer cases were included. Majority of the patients were in the age group 40-49 years (32\%). Histopathological examination of the specimens revealed that serous adenocarcinoma was the commonest $(42.4 \%)$ and the least common being yolk sac tumour $(0.9 \%)$. Majority $(n=49,46.2 \%)$ of the patients presented in stage III. The chief complaint was abdominal pain $(n=74,69.8 \%)$ followed by abdominal distension $(\mathrm{n}=55,51.8 \%)$.

Conclusions: Majority of the patients who presented to us were in the perimenopausal age group at least 2 decades earlier to the western population and many of the patients presented with abdominal pain rather than abdominal distension. These observations warrant us to screen women at an earlier age and also think of this lethal malignancy in women who present with pain and other vague symptoms.

Keywords: Ovarian cancer, Epidemiology, Treatment, Histopathology

\section{INTRODUCTION}

Ovarian cancer is the sixth most common cancer and seventh most common cause of death among women world-wide Japan and Asian countries have rates of 2-6.5 new cases per 100,000 women per year. ${ }^{1,2}$ The prognosis of patients with ovarian cancer is poor, with a 5 year survival of about $35 \%$ Ovarian tumours are often detected in the advanced stage as the symptoms are vague. ${ }^{3}$ Identification of early symptoms may have important clinical implications because 5-year survival for early stage disease is $70 \%$ to $90 \%$ compared with $20 \%$ to $30 \%$ for advanced-stage disease. ${ }^{4}$ As the symptoms are often vague, patients attribute it to other conditions and present late adding to the poor compliance to treatment. Therefore it is very essential to objectively determine not only the histopathology of the ovarian tumour but also symptoms with which the patients present as this can help in the early management of the malignancy. This study will further our understanding on the natural history of the disease and also help in the identification of prognostic markers which may improve the survival rate .The present study was done to study the clinical presentation and histopathological varieties of the ovarian tumours. 


\section{METHODS}

The study was conducted in M S Ramaiah Medical College and teaching hospital between January 2009 and January 2014. Medical records of all 106 ovarian cancer patients admitted during this period were reviewed. The detail history of the patient was collected which included patient age, demographic data, chief complaints, menstrual history - age of menarche, duration of flow, obstetric history - giving the records of number of pregnancy, staging (FIGO), investigations such as radiological studies, histopathology, details of cytoreductive surgery performed and adjuvant chemotherapy received. The collected data was analysed using spss. Chi square test was used for finding statistical significance. $\mathrm{P}$ value $<0.05$ was considered to be statistically significant.

\section{RESULTS}

Table 1: Age distribution.

\begin{tabular}{|ll|}
\hline Age (years) & Number of patients (\%) \\
\hline $10-19$ & $2(1.8 \%)$ \\
\hline $20-29$ & $10(9.4 \%)$ \\
\hline $30-39$ & $12(11.3 \%)$ \\
\hline $40-49$ & $34(32 \%)$ \\
\hline $50-59$ & $25(23.5 \%)$ \\
\hline $60-69$ & $15(14.1 \%)$ \\
\hline$>69$ & $8(7.5 \%)$ \\
\hline
\end{tabular}

Table 2: Stage of ovarian cancer.

\begin{tabular}{|ll|}
\hline Stage I & $\mathbf{1 5}(\mathbf{1 4 . 1} \%)$ \\
\hline Stage II & $7(6.6 \%)$ \\
\hline Stage III & $49(46.2 \%)$ \\
\hline Stage IV & $10(9.4 \%)$ \\
\hline
\end{tabular}

In this study 106 patients with documented pre-operative diagnosis of ovarian cancer admitted to the department of obstetrics and gynaecology, M. S. Ramaiah medical college and teaching hospital, Bangalore were included. Majority of the patients were in the age group 40-49 years $(n=34,32 \%)$. Only 2 of the patients $(1.8 \%)$ were less than 19 years (Table 1). Majority of the patients $(n=49,46.2 \%)$ were admitted to the hospital with stage III disease and 10 patients $(9.4 \%)$ presented with stage IV disease (Table 2). 25 ( $23.5 \%)$ patients came with recurrence. 74 patients $(69.8 \%)$ came to the hospital with abdominal pain and 55 patients presented with abdominal distension $(51.8 \%)$ (Figure 1). Serous adenocarcinoma was the commonest histopathological variety $(n=45$, $42.4 \%)$ followed by mucinous adenocarcinoma $(n=24$, $22.3 \%)$ and the least common was yolk sac tumour. $(n=1$, $0.9 \%$ ). The other histopathological varieties were clear cell adenocarcinoma $(\mathrm{n}=6, \quad 5.6 \%)$, endometrial adenocarcinoma $(n=10,9.4 \%)$, dysgerminoma $(n=9$, $8.4 \%)$, malignant teratoma $(n=5,4.7 \%)$, mixed germ cell tumour $(n=3,2.8 \%)$ and granulosa cell tumour $(n=3$,
$2.8 \%$ ) (Table 3). 10 (9.4\%) patients died within 40 days of surgery. Among them, 6 had stage-IIIC disease, 2 had stage-IV disease, and 2 had recurrent disease. The most common cause of postoperative death was haemorrhagic shock which was noted in 5 of the 10 patients. 2 of the patients were noted to have high grade fever and expired due to sepsis, blood culture was positive to klebsiella. 3 patients were discharged against medical advice and on investigating over a phone call found to have expired within 5 weeks of discharge. Only $54.7 \%$ ( $n=40$ out of 73 patients advised) of the patients showed compliance with chemotherapy.

Table 3: Histopathology.

\begin{tabular}{|ll|}
\hline Type & $\begin{array}{l}\text { Number of patients } \\
(\%)\end{array}$ \\
\hline Serous adenocarcinoma & $45(42.4 \%)$ \\
\hline Mucinous adenocarcinoma & $24(22.3 \%)$ \\
\hline Clear cell adenocarcinoma & $06(5.6 \%)$ \\
\hline Endometroid adenocarcinoma & $10(9.4 \%)$ \\
\hline Dysgerminoma & $09(8.4 \%)$ \\
\hline Malignant teratoma & $05(4.7 \%)$ \\
\hline Yolk sac tumour & $01(0.9 \%)$ \\
\hline Mixed germ cell tumour & $03(2.8 \%)$ \\
\hline Granulosa cell & $03(2.8 \%)$ \\
\hline
\end{tabular}

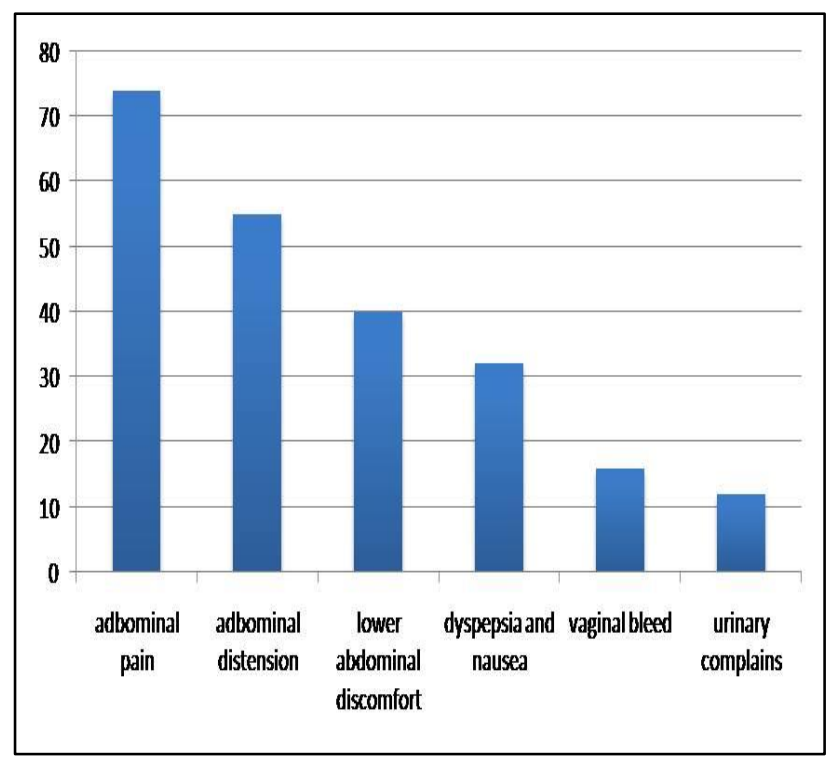

Figure 1: Distribution of symptoms.

\section{DISCUSSION}

Ovarian cancer is the most lethal gynaecologic malignancy. ${ }^{5,6}$ In this study we present the epidemiological and pathological characteristics of the patients with ovarian cancer. The age group in which majority of the ovarian cancers were found was 40-49 years. This is similar to the study by $\mathrm{R}$ Jha et al. in which malignant ovarian tumors are more common above 40 years. $^{7}$ A higher median age of $60-65$ years for malignant 
lesions has been reported from the western countries. ${ }^{8,9}$ The earlier occurrence of the ovarian cancer in our study population and also in other Indian studies compared to the western population as shown in the above studies is a warning call for all clinicians to think of ovarian cancer in any patient who present with vague symptoms. 12 patients in this study were less than 30 years similar to the study by Refaat A Hegazi et al in which seven cases were in patients 30 years old or less. ${ }^{10}$ Nearly $75 \%$ of patients present with advanced stage ovarian cancer. ${ }^{11}$ In our study $59(55.6 \%)$ patients presented in the last stages III and IV (stage III: $n=49,46.2 \%$, stage IV: $n=10,9.4 \%$ ). 85 patients $(80.1 \%)$ were diagnosed with epithelial ovarian cancer. This is similar to most of the other studies like that of $\mathrm{P}$ Basu et al, in which nearly $80 \%$ of all the malignant ovarian tumors were epithelial in origin. ${ }^{12}$ Out of 85 patients with epithelial ovarian cancers, 45 (52.9\%), 24 mucinous adenocarcinoma (28.2\%), 6 clear cell carcinoma (7.05\%), and 10 endometrioid cancer $(11.7 \%)$. Serous adenocarcinoma was the commonest histopathological variety $(n=45,42.4 \%)$ which is consistent with other studies like Kathleen R. Cho et al Endometrioid adenocarcinomas account for $10-20 \%$ of ovarian carcinomas in most older reports but in the more recent series of Seidman and colleagues, only $7 \%$ were endometrioid. $^{13,14}$ In the present study endometrioid tumours contributed to $9.4 \%$ of the ovarian cancers. In a study of 41 patients with malignant ovarian germ cell tumors by Topuz S et al. ${ }^{15} 23(56 \%)$ had dysgerminomas, $8(19.5 \%)$ had mixed germ cell tumors, $3(7.3 \%)$ had yolk sac tumors, $3(7.3 \%)$ had immature teratomas, $2(4.8 \%)$ had squamous cell carcinoma arising from a mature teratoma, $1(2.4 \%)$ had embryonal carcinoma and 1 had choriocarcinoma. In the present study ,there were 18 malignant germ cell tumours in which dysgerminoma was 9 (50\%),mixed germ cell tumours was 3 (16.6\%), 1 had yolk sac tumour $(5.5 \%)$, malignant teratoma in 5 patients $(27.7 \%)$. The commonest symptom in the present study was abdominal pain noticed in 74 patients $(69.8 \%)$. This is similar to a study by Rashid et al, in which $59 \%$ of the patients had abdominal pain while mass/distension was seen in $37 \%$ of the patients. ${ }^{16}$ In the present study the second commonest symptom after abdominal pain was abdominal distension noticed by 55 patients $(51.8 \%)$. The primary mode of treatment is staging laparotomy and debulking surgery which was done in our patients. 1 year mortality was $17 \%$ in a study Refaat A Hegazi et al and in our study 10 patients $(9.4 \%)$ had deaths within 2 months of the diagnosis. ${ }^{10}$

Majority of the patients who presented to us were in the perimenopausal age group at least 2 decades earlier to the western population and many of the patients presented with abdominal pain rather than abdominal distension. These observations warrant us to screen women at an earlier age and also think of this lethal malignancy in women who present with pain and other vague symptoms.

Funding: No funding sources
Conflict of interest: None declared

Ethical approval: Not required

\section{REFERENCES}

1. Parkin DM, Bray F, Ferlay J, Pisani P. Global cancer statistics, 2002. CA Cancer J Clin. 2005;55:74-108.

2. Murad A. Ovulation induction and ovarian tumours: the debate continues. J Pak Med Assoc. 1998;48:353-6.

3. Runnebaum IB, Stickeler E. Epidemiological and molecular aspects ofovarian cancer risk. J Cancer Res Clin Oncol. 2001;127:73-9.

4. Boring CC, Squires TS, Tong T. Cancer statistics.CA Cancer J Clin. 1993;43:7-26.

5. Banks E, Beral V, Reeves G. The epidemiology of epithelial ovarian cancer: a review. Int J Gynecol Cancer. 1997;7:425-38.

6. Parkin DM, Muir CS, Whelan SF. Cancer incidence in five continents. Lyon, France: IARC Scientific, 1992.

7. Jha R, Karki S.Histological pattern of ovarian tumors and their age distribution Nepal Med Coll J. 2008;10(2):81-5.

8. Yancik R. Ovarian cancer. Age contrasts in incidence, histology, disease stage at diagnosis, and mortality. Cancer. 1993;71(Suppl 2):517-23.

9. Quirk JT, Natarajan N. Ovarian cancer incidence in the United States, 1992-99. Gynecol Oncol. 2005;97:519-23.

10. Hegazi RA, Wahab KA, El Nahas W. Epidemiological and Pathological Correlates of Postoperative Mortality ofpatients with Ovarian Cancer Surgery Curr Res. 2013;3:126.

11. Cristea M. Practical considerations in ovarian cancer chemotherapy Ther Adv Med Oncol. 2010;2(3):175-87.

12. Basu P, De P, Mandal S. Study of 'patterns of care' of ovarian cancer patients in a specialized cancer institute in Kolkata, eastern India. Indian $\mathbf{J}$ of Cancer. 2009;46(1):28-33.

13. Kathleen R. Cho and Ie-Ming Shih. Ovarian Cancer Annu Rev Pathol. 2009;4:287-313.

14. Seidman JD, Horkayne-Szakaly I, Haiba M, Boice CR, Kurman RJ, Ronnett BM. The histologic type and stage distribution of ovarian carcinomas of surface epithelial origin. Int $\mathrm{J}$ Gynecol Pathol. 2004;23:41-4.

15. Topuz S, Iyibozkurt AC, Akhan SE, Keskin N, Yavuz E, Salihoglu Y, et al. Malignant germ cell tumors of the ovary: A review of 41 cases and risk factors for recurrence. Eur J Gynaecol Oncol. 2008;29:635-7. 
16. Rashid S, Sarwar G, Ali A. A clinicopathological Study of ovarian cancer. Departments of Radiotherapy and oncology Sir Ganga Ram Hospital and Mayo Hospital Lahore. J Pak Med Assoc. 1998;36;117-25.
Cite this article as: Krishnaswamy $\mathrm{P}$, Nayak $\mathrm{P}$, Shivananjiah C, Swarup A, Cherukumudi A, Chandran PR. Study of clinical presentation and histopathological patterns of ovarian cancer in a tertiary care centre. Int J Community Med Public Health 2016;3:86-9. 